\title{
PERFIL HEMATOLÓGICO DE CABRAS CLINICAMENTE SADIAS CRIADAS NO CARIRI PARAIBANO
}

\author{
Profile hematological of goat clinical healthy servants in Cariri paraibano \\ Leilson Rocha Bezerra ${ }^{1}$, Adriano Fernades Ferreira ${ }^{2}$, Expedito Kennedy Alves Camboim ${ }^{3}$, \\ Soraia Vital Justiniano ${ }^{4}$, Priscila Cristina Rocha Machado ${ }^{4}$, Breno Batista Gomes ${ }^{4}$
}

\begin{abstract}
RESUMO
Objetivou-se com este trabalho estudar o perfil hematológico de cabras sem raça definida, criadas na região do Cariri paraibano em regime semi-intensivo e mantidas sob as mesmas condições ambientais e de manejo, como também a busca de valores de referência que se adeqüem à nossa região. Foram coletadas amostras sanguíneas de 143 animais clinicamente sadios, com idades entre 1 e 12 anos. A partir de uma única amostra de sangue de cada animal foram realizados o eritrograma (contagem de hemácias, volume globular, hemoglobina, volume corpuscular médio, hemoglobina corpuscular média e concentração de hemoglobina corpuscular média) e o leucograma (contagem total e diferencial de leucócitos). Os dados obtidos foram avaliados estatisticamente por meio do Teste de Tukey em nível de significância de 5\%, comparando os resultados com valores encontrados por outros autores. Os resultados demonstraram que não foram evidenciadas diferenças significativas de resultados encontrados por outros autores para as variáveis avaliadas, porém houve diferenças para alguns parâmetros descritos na literatura para animais de mesma raça e faixas etárias, refletindo a influência de fatores como altitude,clima, nutrição e manejo entre outros. Desta forma, evidencia-se a necessidade de pesquisas para o estabelecimento de valores regionais.
\end{abstract}

Termos para indexação: Cabras, hemograma, semi-árido.

\section{ABSTRACT}

On aimed to study the profile hematological of female goats of the sem race defined, raised in the area of Cariri Paraibano at a semi-intensive regime and under the same environmental and management conditions and handling as well as the search for reference values that adequate to our region. Sanguine samples of 143 clinically healthy animals were collected with ages between 1 and 12 years. Starting from just a single sample of blood of each animal the eritrograma was accomplished (Red blood cell count, packed cell volume, hemoglobin, mean corpuscular values, mean corpuscular hemoglobin and mean corpuscular hemoglobin concentration) and the leucograma (, white blood cell count and differential white blood cell count). The obtained data were appraised statistically by means of the Tukey of Test at the level of significance of 5\%, comparing the results with found to other authors. The results demonstrated that significant differences of results were not evidenced found by other authors, however there were differences for some parameters described in the literature for animals of the same race and age groups, reflecting the influence of factors as altitude, climate, nutrition and handling among others. So, the need of researches is evidenced for the establishment of regional values.

Index terms: Goats, hematology, semi-arid.

(Recebido em 15 de agosto de 2006 e aprovado em 9 de julho de 2007)

\section{INTRODUÇÃO}

A criação de caprinos é bastante difundida no mundo, sendo criados nas mais diversas regiões; muitas vezes, em situações inóspitas tanto nutricionais como ambientais; o que, geralmente, prejudica sua eficiência produtiva e reprodutiva. Nos últimos anos, tem se observado um crescimento significativo da caprinocultura no país em detrimento da criação de animais de grande porte como os bovinos, em consequência das inúmeras vantagens que apresentam como a necessidade de uma menor área de criação, menor consumo de alimento, facilidade de manejo e uma boa diversidade de produção como carne, leite e couro de boa qualidade.

O Brasil possui cerca de 12,8 milhões de caprinos, sendo detentor do nono rebanho do mundo, tendo havido um acréscimo de 50,6\% do seu rebanho no período entre 1980 e 1992 (CORDEIRO, 1998). Daquele total, 92\% estão concentrados na região Nordeste, sendo o estado da

${ }^{1}$ Médico Veterinário, Doutorando em Zootecnia - Departamento de Zootecnia/DZ - Centro de Ciências Agrárias/CCA - Universidade Federal da Paraíba/ UFPB - Rua Pau D'Arco - Avenida dos Universitários - 58397-000 - Areia, PB - leilsonbezerra@hotmail.com

${ }^{2}$ Mestre em Medicina Veterinária, Professor - Departamento de Medicina Veterinária/DMV - Centro de Saúde e Tecnologia Rural/CSTR - Universidade Federal de Campina Grande/UFCG - Rodovia Patos-Teixeira, s/n - Cx.P. 64 - 58700-970 - Patos, PB - adriano@cstr.ufcg.edu.br

${ }^{3}$ Médico Veterinário, Mestrando em Medicina Veterinária - Departamento de Medicina Veterinária/DMV - Centro de Saúde e Tecnologia Rural/CSTR Universidade Federal de Campina Grande/UFCG - Rodovia Patos-Teixeira, s/n - Cx.P. 64 - 58700-970 - Patos, PB - expeditovet@hotmail.com ${ }^{4}$ Médicos Veterinários - Departamento de Medicina Veterinária/DMV - Centro de Saúde e Tecnologia Rural/CSTR - Universidade Federal de Campina Grande/UFCG - Rodovia Patos-Teixeira, s/n - Cx.P. 64 - 58700-970 - Patos, PB - soraiavet@hotmail.com; priscila_crm@hotmail.com; brenobvet@bol.com.br 
Paraíba possuidor de aproximadamente um milhão de caprinos.

São relativamente escassas as pesquisas direcionadas à espécie caprina na nossa região, sobretudo referente ao conhecimento do perfil hematológico da espécie. O que se observa na verdade é que a maioria dos trabalhos referentes à hematologia de caprinos baseia-se em valores procedentes de outras regiões com condições de manejo, alimentação e clima diferentes do nosso, além de referências à idade e ao sexo.

Segundo Ayres (1994) os exames laboratoriais são muito importantes na Medicina Veterinária, pois, além de ajudar o clínico no diagnóstico e prognóstico de patologias, orienta-o no tratamento das mesmas. A hematologia dos animais domésticos é um assunto antigo e ao mesmo tempo atual, pois em pleno século XXI, época de grande desenvolvimento e expansão tecnológica, o tema ainda não demonstrou estar exaurido, uma vez que muitos são os fatores de variabilidade que influenciam o quadro hematológico e que continuam ainda não elucidados satisfatoriamente. Assim, diversos pesquisadores da área têm procurado nas mais variadas regiões do mundo, estabelecer valores padrões para os animais domésticos levando em consideração fatores individuais como raça, sexo e idade, além de outros relacionados às características ambientais como clima, altitude e o manejo de forma geral, bem como condições fisiopatológicas que também possam influenciar nos valores pesquisados.

Esta pesquisa objetivou estudar a influência da idade sobre o quadro hematológico de caprinos sem raça definida e estabelecer valores de referência para a região do semi-árido paraibano, uma vez que os valores referenciais utilizados na região são oriundos de pesquisas de outras regiões com clima, pastagens, sistema de criação e animais de linhagem genética diferentes.

\section{MATERIAL E MÉTODOS}

O experimento foi conduzido no Centro de Saúde e Tecnologia Rural da Universidade Federal de Campina Grande. Para tanto, foram utilizadas 143 cabras sem raça definida (SRD), criadas na região semi-árida do Cariri paraibano, sob as mesmas condições de manejos sanitário, nutricional e ambiental. Todos os animais foram criados na região do Cariri da Paraíba, em regime semi-extensivo e sua alimentação compunha-se de capim Búfel (Cenchrus ciliaris,L.), palma forrageira (Opuntia fícus indica, MILL) e concentrado industrializado. Recebiam ainda, água e sal mineral à vontade. Eles eram vermifugados periodicamente. Mesmo assim, procedeu-se uma colheita de fezes, diretamente na ampola retal, para realização de exames parasitológicos com o objetivo de se certificar de que os mesmos encontravam-se isentos de verminoses ou com baixa carga parasitária.
Antes da colheita de sangue, os caprinos foram submetidos a um rigoroso exame clínico, no qual eram verificadas a temperatura retal, freqüência respiratória, ausculta cardíaca, exames de mucosas, exames de linfonodos e avaliação de grau de desidratação, segundo técnicas semióticas preconizadas por Rosemberger (1993). A seguir, procedia-se à colheita de sangue através de punção da veia jugular, utilizando-se agulhas descartáveis 40x12 mm e deposição em frasco de vidro tipo vacutainer reutilizado contendo $0,05 \mathrm{ml}$ de uma solução aquosa a $10 \%$ de etileno-diamino-tetracetato de sódio (EDTA) para cada cinco $\mathrm{ml}$ de sangue colhido. As amostras eram mantidas em isopor com gelo até sua chegada ao Laboratório de Patologia Clínica do Hospital Veterinário-CSTR-UFCG, onde, num prazo de 24 horas, concluía-se o hemograma que consistia de contagem do número de hemácias, determinação do volume globular, teor de hemoglobina, índices hematimétricos absolutos, contagem do número de leucócitos e contagem diferencial de leucócitos.

A contagem do número de hemácias e leucócitos foi realizada em câmara do tipo Neubauer modificada e, para tanto, a diluição das células foi feita utilizando-se pipeta semi-automática de 20 microlitros, conforme preconizado por Vallada (1999), Para determinação do volume globular, utilizou-se a técnica do microhematócrito, conforme descrito por Ayres (1994), na qual se utilizaram tubos capilares homogêneos de 75 milímetros de comprimento por um milímetro de diâmetro. A determinação do teor de hemoglobina no sangue foi feita pelo método do cianometahemoglobina, conforme descrito por Melo (2001) utilizando Analisador bioquímico automático (BIOPLUS®).

Os valores obtidos com a contagem do número de hemácias, do volume globular e com a determinação do teor de hemoglobina permitiram-nos estabelecer os valores dos índices hematimétricos absolutos, mediante prévia digitação dos valores em aparelho específico para contagem diferencial de leucócitos, conforme descrito por Ayres (1994). A contagem diferencial de leucócitos era feita através de esfregaço sanguíneo seguindo a metodologia descrita por Coles (1984).

Os resultados obtidos para os constituintes do eritrograma e do leucograma foram submetidos à análise de variância e ao teste de Tukey a 5\%, para comparação de médias, verificando-se a influência do fator etário (SAMPAIO, 1998).

\section{RESULTADOS E DISCUSSÃO}

Os resultados obtidos dos 143 eritrograma e leucograma, realizados em amostras de sangue colhidas de caprinos sem raça definida, clinicamente sadios, para avaliação da influência do fator etário e com o intuito de se 
estabelecer valores que se adeqüem à realidade da região do Cariri paraibano, estão apresentados em quatro tabelas, formuladas segundo objetivou-se com esta pesquisa e, cada parâmetro será discutido individualmente.

Na Tabela 1, temos os resultados obtidos da média, do desvio-padrão, valores mínimo e máximo para os parâmetros estudados na pesquisa, sem levar em consideração a influência do fator etário.

Nas Tabelas 2 e 3, levando-se em consideração o fator etário sobre o eritrograma e o leucograma de caprinos fêmeas sem raça definida, estão expressos os resultados obtidos no experimento.

Pela ocorrência de erros inerentes às tentativas do cálculo de valores médios e desvios padrão da média a partir de valores apresentados em porcentagens, na apresentação dos resultados da presente pesquisa, optouse pela utilização dos valores absolutos, aceitando-se, portanto, as recomendações de Birgel (1982) de que essa seria a forma mais representativa para a apresentação dos resultados relacionados ao leucograma. Nas pesquisas realizadas no Brasil, referentes ao quadro hematológico de caprinos, poucas pesquisas (BIRGEL, 1991; FERREIRA NETO, 1986; VIANA et al., 2002) optam pela apresentação dos resultados em valores absolutos, afirmando-se o número das células existentes na unidade de sangue.

A interpretação da afirmação exposta anteriormente ressalta, de forma expressiva, a necessidade e a premência de estudar-se melhor o quadro hemático de caprinos criados no Brasil para expressar a realidade da região estudada. Dessa forma, justificam-se os poucos resultados encontrados na literatura.

Através da avaliação da Tabela 1, observamos que o número de hemácias da presente pesquisa foi semelhante àqueles obtidos por diversos pesquisadores (FERREIRA NETO et al., 1986; JAIN, 1986; MELO, 2001; NETLLETON \& BECKETT, 1976). Não foram observadas diferenças estatísticas $(\mathrm{P}<0,05)$ do número de eritrócitos, levando em consideração variação etária (Tabela 4), demonstrando a pouca variabilidade entre animais que estão sob as mesmas condições fisiológicas e de manejo. Comparando-se os resultados do número total de leucócitos, obtidos na presente pesquisa com aqueles referidos na literatura brasileira (FERREIRA NETO et al., 1986; MARQUES JÚNIOR et al., 1990; MATOS et al., 1982) verificou-se que os valores eram semelhantes, pois os valores médios obtidos nessas pesquisas para o número de leucócitos, encontram-se dentro das amplitudes de variação, correspondente a média \pm um desvio padrão, obtida na presente pesquisa. No tocante à variável idade, pode-se afirmar, de acordo com a Tabela 4 , que não houve diferença estatística $(\mathrm{P}<0,05)$. Na literatura (BIRGEL, 1991; FERREIRA NETO et al., 1986; VIANA et al., 2002) evidencia-se que em cabras não gestantes, na fase inicial e na fase média da gestação e em cabritos com menos de 12 meses de idade, o número de leucócitos é elevado devido a predominâncias dos linfócitos. Esse quadro leucocitário, entretanto, passa a ser neutrofílico nos caprinos adultos (BIRGEL, 1991), o que não foi observado no quadro leucocitário analisado na presente pesquisa.

Tabela 1 - Valores médios do eritrograma e do leucograma de 143 cabras sem raça definida, criados em rebanhos da Região do Cariri paraibano.

\begin{tabular}{lccrr}
\hline \multicolumn{1}{c}{ Parâmetros } & Média & Desvio Padrão & Valor mínimo & Valor máximo. \\
\hline Hemácias $\left(\mathrm{x} 10^{6} \mathrm{~mm}^{3}\right)$ & 14,48 & $\pm 2,36$ & 8,6 & 20,0 \\
Hemoglobina $(\mathrm{g} / \mathrm{dl})$ & 9,0 & $\pm 1,0$ & 6,0 & 13,0 \\
Hematócrito $(\%)$ & 27,0 & $\pm 3,0$ & 18,0 & 38,0 \\
VCM $\left(\mu^{3}\right)$ & 19,0 & $\pm 2,0$ & 10,0 & 28,0 \\
HCM $(\mathrm{pg})$ & 6,0 & $\pm 1,0$ & 3,0 & 9,0 \\
CHCM $(\%)$ & 34,0 & $\pm 3,0$ & 25,0 & 47,0 \\
Leucócitos $(\mathrm{n} / \mathrm{ml})$ & 11832 & \pm 3168 & 3350 & 21850 \\
Segmentados $(\mathrm{n} / \mathrm{ml})$ & 5526 & \pm 2075 & 370 & 11552 \\
Bastonetes $(\mathrm{n} / \mathrm{ml})$ & 15 & \pm 45 & 0 & 242 \\
Linfócitos $(\mathrm{n} / \mathrm{ml})$ & 5547 & \pm 272 & 2278 & 13350 \\
Monócitos $(\mathrm{n} / \mathrm{ml})$ & 143 & \pm 552 & 0 & 6528 \\
Basófilos $(\mathrm{n} / \mathrm{ml})$ & 3 & \pm 22 & 0 & 198 \\
Eosináofilos $(\mathrm{n} / \mathrm{ml})$ & 412 & \pm 468 & 0 & 2997 \\
\hline
\end{tabular}

$\mathrm{VCM}$ = volume corpuscular médio, $\mathrm{HCM}$ = hemoglobina corpuscular média, $\mathrm{CHCM}$ = concentração de hemoglobina corpuscular média. 
Tabela 2 - Valores médios do eritrograma e do leucograma de cabras jovens com idade até 24 meses sem raça definida, em rebanhos da Região do Cariri paraibano.

\begin{tabular}{lcccc}
\hline \multicolumn{1}{c}{ Parâmetros } & Media & Desvio Padrão & Valor mínimo & Valor máximo \\
\hline Hemácias $\left(\times 10^{6} \mathrm{~mm}^{3}\right)$ & 14,66 & $\pm 2,71$ & 8,6 & 20,0 \\
Hemoglobina $(\mathrm{g} / \mathrm{dl})$ & 9,0 & $\pm 1,0$ & 6,0 & 13,0 \\
Hematócrito $(\%)$ & 27,0 & $\pm 3,0$ & 20,0 & 33,0 \\
VCM $\left(\mu^{3}\right)$ & 18,0 & $\pm 2,0$ & 13,0 & 28,0 \\
HCM $(\mathrm{pg})$ & 6,0 & $\pm 1,0$ & 4,0 & 8,0 \\
CHCM $(\%)$ & 34,0 & $\pm 3,0$ & 26,0 & 47,0 \\
Leucócitos $(\mathrm{n} / \mathrm{ml})$ & 12458 & \pm 3736 & 4200 & 21850 \\
Segmentados $(\mathrm{n} / \mathrm{ml})$ & 5216 & \pm 2202 & 370 & 11552 \\
Bastonetes $(\mathrm{n} / \mathrm{ml})$ & 20 & \pm 52 & 0 & 242 \\
Linfócitos $(\mathrm{n} / \mathrm{ml})$ & 6333 & \pm 2760 & 936 & 13110 \\
Monócitos $(\mathrm{n} / \mathrm{ml})$ & 136 & \pm 143 & 0 & 594 \\
Basófilos $(\mathrm{n} / \mathrm{ml})$ & 7 & \pm 33 & 0 & 198 \\
Eosináofilos $(\mathrm{n} / \mathrm{ml})$ & 351 & \pm 305 & 0 & 1188 \\
\hline VCM & & & 0 & \\
\hline
\end{tabular}

VCM = volume corpuscular médio, HCM = hemoglobina corpuscular média, CHCM = concentração de hemoglobina corpuscular média.

Tabela 3 - Valores médios do eritrograma e do leucograma de cabras adultas lactantes com idade 24 meses sem raça definida, criados em rebanhos da Região do Cariri paraibano.

\begin{tabular}{lcccc}
\hline \multicolumn{1}{c}{ Parâmetros } & Media & Desvio Padrão & Valor mínimo & Valor máximo \\
\hline Hemácias $\left(\times 10^{6} \mathrm{~mm}^{3}\right)$ & 14,35 & $\pm 2,10$ & 9,98 & 20,0 \\
Hemoglobina $(\mathrm{g} / \mathrm{dl})$ & 9,0 & $\pm 1,0$ & 6,0 & 13,0 \\
Hematócrito $(\%)$ & 27,0 & $\pm 4,0$ & 18,0 & 38,0 \\
VCM $\left(\mu^{3}\right)$ & 19,0 & $\pm 2,0$ & 10,0 & 25,0 \\
HCM $(\mathrm{pg})$ & 6,0 & $\pm 1,0$ & 3,0 & 9,0 \\
CHCM $(\%)$ & 33,0 & $\pm 2,0$ & 25,0 & 13,0 \\
Leucócitos $(\mathrm{n} / \mathrm{ml})$ & 11417 & \pm 2672 & 3350 & 9900 \\
Segmentados $(\mathrm{n} / \mathrm{ml})$ & 5731 & \pm 1973 & 670 & 237 \\
Bastonetes $(\mathrm{n} / \mathrm{ml})$ & 11 & \pm 39 & 0 & 13335 \\
Linfócitos $(\mathrm{n} / \mathrm{ml})$ & 5026 & \pm 1811 & 272 & 6528 \\
Monócitos $(\mathrm{n} / \mathrm{ml})$ & 147 & \pm 705 & 0 & 66 \\
Basófilos $(\mathrm{n} / \mathrm{ml})$ & 1 & \pm 7 & 0 & 2997 \\
Eosináofilos $(\mathrm{n} / \mathrm{ml})$ & 453 & \pm 548 & 0 & \\
\hline VCM
\end{tabular}

VCM = volume corpuscular médio, $\mathrm{HCM}=$ hemoglobina corpuscular média, $\mathrm{CHCM}$ = concentração de hemoglobina corpuscular média.

A inversão do quadro leucocitário de caprinos com o evoluir da idade, passando de linfocitário para neutrofílico deve-se não propriamente à influência da idade, mas sim refletem as modificações ocorridas com as mudanças fisiológicas como é o caso de animais gestantes e no puerpério quando essas mudanças são mais notórias, o que não foi evidenciado na presente pesquisa que comparou animais sadios e todos não gestantes.

As médias obtidas na presente pesquisa para o teor de hemoglobina, volume globular, volume corpuscular médio, hemoglobina corpuscular média e concentração de hemoglobina corpuscular média (Tabela 1) foram semelhantes àquelas descritas em diversas pesquisas consultadas (JAIN, 1986; MELLO, 2001) e diferenciaramse dos valores apresentados por Holman \& Dew (1963), Lewis (1997) e Repetti (1997). Quando confrontados os dois grupos etários (Tabela 4), não se observou influência da idade para nenhuma das variáveis $(\mathrm{P}<0,05)$. Variações relacionadas aos índices hematimétricos são comuns para animais em diferentes estados fisiológicos, onde os mesmos tendem a diminuir com o avanço da gestação (FORTAGNE \& SCHAFER, 1989), animais parasitados e animais em estresse térmico. Já para animais sadios, nas mesmas condições fisiológicas e de manejo não são 
Tabela 4 - Valores médios comparativos do eritrograma e do leucograma de cabras adultas lactantes com idade 24 meses e cabras jovens de até 24 meses sem raça definida, com OPG até 500, criados em rebanhos da Região do Cariri paraibano.

\begin{tabular}{lll}
\hline \multicolumn{1}{c}{ Parâmetros } & Até 24 meses & Acima 24 meses \\
\hline Hemácias $\left(\mathrm{x} 10^{6} \mathrm{~mm}^{3}\right)$ & $14,66( \pm 2,71)$ & $14,35( \pm 2,10)$ \\
Hemoglobina $(\mathrm{g} / \mathrm{dl})$ & $9,0( \pm 1,0)$ & $9,0( \pm 1,0)$ \\
Hematócrito $(\%)$ & $27,0( \pm 3,0)$ & $27,0( \pm 4,0)$ \\
VCM $\left(\mu^{3}\right)$ & $18,0( \pm 2,0)$ & $19,0( \pm 2,0)$ \\
HCM $(\mathrm{pg})$ & $6,0( \pm 1,0)$ & $6,0( \pm 1,0)$ \\
CHCM $(\%)$ & $34,0( \pm 3,0)$ & $33,0( \pm 2,0)$ \\
Leucócitos $(\mathrm{n} / \mathrm{ml})$ & $12458( \pm 3736)$ & $11417( \pm 2672)$ \\
Segmentados $(\mathrm{n} / \mathrm{ml})$ & $5216( \pm 2202)$ & $5731( \pm 1973)$ \\
Bastonetes $(\mathrm{n} / \mathrm{ml})$ & $20( \pm 52)$ & $11( \pm 39)$ \\
Linfócitos $(\mathrm{n} / \mathrm{ml})$ & $6333( \pm 2760)$ & $5026( \pm 1811)$ \\
Monócitos $(\mathrm{n} / \mathrm{ml})$ & $136( \pm 143)$ & $147( \pm 705)$ \\
Basófilos $(\mathrm{n} / \mathrm{ml})$ & $7( \pm 3)$ & $1( \pm 7)$ \\
Eosináofilos $(\mathrm{n} / \mathrm{ml})$ & $351( \pm 305)$ & $453( \pm 548)$ \\
\hline
\end{tabular}

VCM = volume corpuscular médio, HCM = hemoglobina corpuscular média, $\mathrm{CHCM}=$ concentração de hemoglobina corpuscular média.

evidenciadas diferenças. No presente trabalho procurouse estabelecer valores que podessem ser usados como referencia clínica demonstrando a realidade encontrada ao realizar hemograma de animais enfermos.

\section{CONCLUSÃO}

Os resultados demonstraram que não foram evidenciadas diferenças significativas entre os valores encontrados para o hemograma das cabras, nas condições do experimento, e os resultados encontrados pela maioria dos autores citados, para as variáveis avaliadas, executando experimentos em condições semelhantes às do presente trabalho.

Os fatos anteriormente discutidos evidenciam, de forma notória, a necessidade da realização de estudos para se determinar os valores de referência do hemograma dos caprinos criados nas condições brasileiras de manejo e alimentação, bem como a avaliação dos fatores de variação sobre os constituintes do sangue.

\section{AGRADECIMENTOS}

Ao Sebrae, pelo auxilio financeiro.

\section{REFERÊNCIAS BIBLIOGRÁFICAS}

AYRES, M. C. C. Eritrograma de Zebuínos (Bos indicus, Linnaeus, 1759) da raça Nelore, criados no Estado de São Paulo, influência dos fatores etário, sexual e do tipo racial. São Paulo: [s.n.], 1994.
BIRGEL, E. H. Estudo do quadro leucocitário de caprinos (Capra hircus, L.) normais, criados no Estado de São Paulo: influência dos fatores raciais, sexuais, etários e alimentares. 1969. 113 f. Tese (Doutorado) - Universidade de São Paulo, São Paulo, 1969.

BIRGEL, E. H. Hematologia clínica veterinária. In: BIRGEL, E. H.; BENESI, F. J. Patologia clínica veterinária. São Paulo: Sociedade Paulista de Medicina Veterinária, 1982. p. 2-34.

COLES, E. H. Patologia clínica veterinária. 3. ed. São Paulo: Manole, 1984. $566 \mathrm{p}$.

CORDEIRO, P. R. C. Opções de mercado de leite de cabra e derivados. In: ENCONTRO NACIONAL PARA O DESENVOLVIMENTO DA ESPÉCIE CAPRINA, 5., 1998, Botucatu. Anais... Botucatu: UNESP; Associação Paulista dos Criadores de Caprinos, 1998. p. 57-60.

FERREIRA NETO, J. M.; MARQUES JÚNIOR, A. P.; CARVALHO, M. M.; FERREIRA, P. M. Hemograma de caprinos do nascimento até um ano de idade. Arquivo Brasileiro de Medicina Veterinária e Zootecnia, Belo Horizonte, v. 38, n. 5, p. 645-656, 1986.

FORTAGNE, M.; SCHAFER, M. Hematologic parameters of Probstheidaer pigmy goats in relation to pregnancy and lactation. Archivos Exp. Veterinary Medicine, [S.1.], v. 43, p. 223-230, 1989. 
HOLMAN, H. H.; DEW, S. M. The blood picture of the goat: I. the two year old female goat. Research Veterinary Science, Oxford, v. 4, p. 121-130, 1963.

JAIN, N. C. Schalm's veterinary hematology. 4. ed. Philadelphia: Lea \& Febinger, 1986. 1221 p.

LEWIS, J. M. Comparative hematology studies on goats. American Journal Veterinary Research, Shaumburg, v. 38, n. 12, p. 2089-2090, 1997.

MARQUES JÚNIOR, A. P.; SILVA, T. M. F.; BATISTA, R. A. Hemograma de cabras leiteiras nos períodos pré e pósparto, mantidas em confinamento. Arquivo Brasileiro de Medicina Veterinária e Zootecnia, Belo Horizonte, v. 42, n. 3, p. 187-195, 1990.

MATOS, M. S.; SOUZA, R. M.; SANTOS, L. M. M.; RIBEIRO, O. C.; SANTOS, J. A. C.; BORGES, W. M. Hemoglobina, volume globular e leucócitos em caprinos. Arquivo da Escola de Medicina Veterinária da UFBA, Ilhéus, v. 7, n. 1, p. 82-90, 1982.

MELO, M. T. Hemograma referencial de caprinos criados no Estado de Pernambuco: procedimentos clínicolaboratoriais e avaliação da influência dos fatores etário e sexual. 2001. 72 f. Dissertação (Mestrado em Medicina
Veterinária - Clínica Médica) - Universidade Federal Rural de Pernambuco, Recife, 2001.

NETTLETON, P.; BECKETT, P. Hematology of the indigenous goat in Swaziland. Tropical Animal Health Production, Edinburg, v. 8, n. 1, p. 60-61, 1976.

REPETTI, E.; SOERENSEN, B.; BARROS, A. R. Valores normais do quadro hematológico dos animais domésticos. Unimar Ciências, Marília, v. 6, n. 1, p. 19-26, jan. 1997.

ROSEMBERGER, G. Exame clínico dos bovinos. 3. ed. Rio de Janeiro. Guanabara Koogan, 1993. 419 p.

SAMPAIO, I. B. M. Estatística aplicada à experimentação animal. Belo Horizonte: Fundação de Ensino e Pesquisa em Medicina Veterinária e Zootecnia, 1998. 221 p.

VALLADA, E. P. Manual de técnicas hematológicas. São Paulo: Atheneu, 1999. 423 p.

VIANA, R. B.; BIRGEL JUNIOR, E. H.; AYRES, M. C. C.; BIOJONI, F. S. M.; SOUZA, M. C. C.; BIRGEL, E. H. Influência da gestação e do puerpério sobre o leucograma de caprinos da raça Saanen, criados no Estado de São Paulo. Brazilian Journal Veterinary Research Animal Science, São Paulo, v. 39, n. 4, p. 196-201, 2002. 